\title{
Deposit accounts
}

\section{Donald Hawkes}

Ore Geology Reviews. Editor-in-chief K.H. Wolf. Elsevier. 4/yr. Dfl. 271.

THis journal purports to be a sequel to the 14 volumes of the Handbook of StrataBound and Stratiform Ore Deposits issued during 1976, 1981 and 1985. Many of the review articles in those volumes encouraged further original research, and if this new journal attains the same standard it will be an essential addition to every major geological library. It is under the same editor, who has stimulating ideas about the nature and concept of review articles, so that the prospects of success must be rated as high.

Publication is intended as four issues per volume, and one volume per year, but a subscriber may not get four separate issues through the mail each year. In 1986. numbers $2-4$ were included in the same cover; these constituted a special issue under a guest editor and consisted of updated papers originally presented at a symposium on "Metallogeny and Tectonic Development of Eastern Australia" held at the Seventh Convention of the

ANNOUNCING A PIONEERING BREAKTHROUGH IN SYSTEMS APPLICATIONS A Synthesis of the Social Sciences

THE CULTURAL SCIENCE OF MAN A NEW SYNTHESIS Bernice Cohen

3 volume set $\mathrm{H} / \mathrm{bk} \& \mathrm{p} / \mathrm{bk}$ Approx $1170 \mathrm{pps}$

PUBLICATION DATE 16th February 1988

If your have any interest in System Theory or in mankind - past, present or future these three books are priority reading!

- Use of orthodox systems analysis techniques to investigate humanity taking MAN as a specific case study

- New classification of culture

- New theory on learned human behaviour

- Totally new economic theory GLOBAL ECONOMICS constructed on systems principles

- Fascinating insights into the use of systems concepts in applied situations

Write now for further details

including prepublication offers to:

Codek Publications

Marketing Department Freepost,

2 Powys Lane, Idon N14 7BR Tel. No. 01-882 4686

Reader Service No.56
Geological Society of Australia in 1984.

The length of articles falls between that of the usual shorter journal reviews and comprehensive book-type coverage and, to this extent, the journal does fill a gap in the literature. The contributions are of high quality; some are definitive, but because they err on the long side and contain considerable detail they require a sustained commitment by a reader who has only a peripheral interest or is unfamiliar with the subject concerned. Unless the emphasis changes, this is unlikely to be a journal a reader will consult to obtain a rapid overview of developments outside his own field.

The print and page style is unremarkable Elsevier. Monochrome photographs, diagrams and tables are accommodated. Probably because the journal is new, admonishments to authors on the limitations set by the size and layout of the journal do not appear to be rigidly enforced. Large fold-out diagrams are accepted in exceptional circumstances.
Each article is accompanied by a passport photograph of the author(s), together with brief biographical details.

The title of the journal is unfortunate and will be misleading to many (?most) geologists because articles are solicited on almost any subject related to both metalliferous and non-metalliferous mineral deposits. Suggested topics include, for example, industrial minerals, pollution studies related to exploration and mining, "land based and oceanic studies", remote sensing, computer geology and exploration techniques. If the journal continues to publish thematic studies taking up two or more issues under a single cover, then a private subscriber might have to wait a considerable time before an article on his speciality appears. For the moment, I would suggest the best course is to borrow a copy from a library and hope that individual numbers may be offered for sale.

Donald Hawkes is Professor in the Department of Geological Sciences, Aston University, Aston Triangle, Birmingham B4 $7 E T, U K$.

\section{Sea changes of the past}

\section{Malcolm B. Hart}

Paleoceanography. Editor James P. Kennett. American Geophysical Union, Washington, DC. 6/yr. $\$ 100$ (institutional), $\$ 34$ (individual $A G U$ members).

THE subject area covered by Paleoceanography is a highly competitive one, which is already served by journals such as Marine Geology, Marine Micropalaeontology and Marine and Petroleum Geology. Initiating a new publication in this field would therefore appear to be a risky venture. However, Paleoceanography is currently attracting contributions of high quality. Its success no doubt stems both from the reputation of the editor and also from the low cost. The penalty for the latter is the use of camera-ready copy. Although many of the papers have reproduced well, others are less good, and in any case some readers are put off by a journal that looks like a typist's manual.

All of the issues sent to me for review contain papers of standard size and coverage. No reviews as such have been printed; nor have any short communications or discussions appeared. One issue (Vol.2, No.2) contained a thematic set of papers on Palaeozoic midcontinental seaways. One drawback of the camera-ready format is that there is no identifiable house style in terms of headings; for cxample, some authors use "Summary", others use "Conclusions". Perhaps this doesn't matter too much, but it does mean that reprints are not readily identifiable as coming from the same source.

The illustrations can, however, be more of a problem, especially when using the double-column format. Authors (and this goes for other double-column journals as well) often fail to make diagrams fit either one column or two. The result is that either a lot of expensive paper is wasted or figures are overly compressed to fit into one column (see Droste and Shaver. Vol.2, No.2). In a subject area that relies heavily on maps and diagrams, editors must resist this temptation and give figures enough space. The other aspect that is a constant headache is that of half-tones, especially when they show palaeontological material. Photograph quality is very important and although the plates of Barrera et al. (Vol.2, No.1) are very good, those of Ciesielski and Grinstead (Vol.1, No.2) are really not acceptable.

Thus far the editor does appear to have a good flow of high-quality papers. I hope this will continue. But the competition for such papers is intense, and unless the photographic quality is consistently high, Marine Micropalaeontology, Micropaleontology, Journal of Foraminiferal Research and other competitors will retain much of the palaeontological market. Although the loss of the biological input would not be fatal, it would indeed be unfortunate.

Ultimately, as libraries review their holdings and budgets, this journal may survive on price alone. But I would like to see it succeed on more scientific grounds.

Malcolm B. Hart is Professor of Micropalaeontology and Head of Department of Geological Sciences, Plymouth Polytechnic, Drake Circus, Plymouth PL4 8AA, UK. 